\title{
Regulation of myoglobin in hypertrophied rat cardiomyocytes in experimental pulmonary hypertension
}

\author{
E. L. Peters ${ }^{1}$ - C. Offringa ${ }^{1}$ - D. Kos ${ }^{1,2} \cdot$ W. J. Van der Laarse $^{2} \cdot$ R. T. Jaspers ${ }^{1}$
}

Received: 3 June 2016 /Revised: 21 July 2016 / Accepted: 4 August 2016 / Published online: 30 August 2016

(C) The Author(s) 2016. This article is published with open access at Springerlink.com

\begin{abstract}
A major problem in chronic heart failure is the inability of hypertrophied cardiomyocytes to maintain the required power output. A Hill-type oxygen diffusion model predicts that oxygen supply is limiting in hypertrophied cardiomyocytes at maximal rates of oxygen consumption and that this limitation can be reduced by increasing the myoglobin $(\mathrm{Mb})$ concentration. We explored how cardiac hypertrophy, oxidative capacity, and $\mathrm{Mb}$ expression in right ventricular cardiomyocytes are regulated at the transcriptional and translational levels in an early stage of experimental pulmonary hypertension, in order to identify targets to improve the oxygen supply/demand ratio. Male Wistar rats were injected with monocrotaline to induce pulmonary hypertension $(\mathrm{PH})$ and right ventricular heart failure. The messenger RNA (mRNA) expression levels per nucleus of growth factors insulin-like growth factor-1Ea (IGF-1Ea) and mechano growth factor (MGF) were higher in PH than in healthy controls, consistent with a doubling in cardiomyocyte cross-sectional area (CSA). Succinate dehydrogenase (SDH) activity was unaltered, indicating that oxidative capacity per cell increased. Although the $\mathrm{Mb}$ protein concentration was unchanged, $\mathrm{Mb}$ mRNA concentration was reduced. However, total RNA per nucleus was about threefold higher in $\mathrm{PH}$ rats versus controls, and $\mathrm{Mb}$ mRNA content expressed per nucleus was similar in the two groups. The increase in oxidative capacity without an increase in oxygen supply via Mb-facilitated diffusion caused a doubling
\end{abstract}

R. T. Jaspers

r.t.jaspers@vu.nl

1 Laboratory for Myology, Faculty of Behavioral and Movement Sciences, Department of Human Movement Sciences, MOVE Research Institute Amsterdam, Vrije Universiteit Amsterdam, van der Boechorststraat 7, 1081, BT Amsterdam, The Netherlands

2 Department of Physiology, Institute for Cardiovascular Research, VU University Medical Center, Amsterdam, The Netherlands of the critical extracellular oxygen tension required to prevent hypoxia $\left(\mathrm{PO}_{2 \text { crit }}\right)$. We conclude that $\mathrm{Mb}$ mRNA expression is not increased during pressure overload-induced right ventricular hypertrophy and that the increase in myoglobin content per myocyte is likely due to increased translation. We conclude that increasing $\mathrm{Mb}$ mRNA expression may be beneficial in the treatment of experimental PH.

Keywords Myoglobin · Heart failure - Oxidative capacity · Pulmonary hypertension · Hypertrophy · Growth factor . Cardiac myocyte $\cdot$ Protein synthesis $\cdot$ Protein degradation . Mitochondrial biosynthesis

\section{Introduction}

Myoglobin is an oxygen buffer and transporter and substantially contributes to mitochondrial oxygen supply, particularly at low intracellular oxygen tension $(<10 \mathrm{mmHg})$ [63]. The myoglobin content is decreased in several models of chronic heart failure (CHF), including dog, turkey, and chicken models, which correlates with biochemical and physiological markers of myocardial performance [33]. A decrease in myoglobin $(\mathrm{Mb})$ concentration has also been reported in rat models of pulmonary hypertension $(\mathrm{PH})$ with progressive heart failure (HF) $[22,40,53]$ but not with stable $\mathrm{HF}[31,40]$. Furthermore, a reduction of $\mathrm{Mb}$ was observed in necropsies of the right-sided myocardium of pulmonary hypertensive patients [40]. These studies suggest that $\mathrm{Mb}$ deficiency may be a determinant of the progression of CHF due to chronic pressure overload.

Apart from oxygen transport and buffering, $\mathrm{Mb}$ also facilitates intracellular fatty acid transport and regulates fatty acid metabolism [50]. This is emphasized by the observation that heart muscle in mice lacking $\mathrm{Mb}\left(\mathrm{myo}^{--}\right.$) switches towards glycolytic metabolism [10]. Mb also 
regulates oxygen supply and consumption by generation and/or scavenging of nitric oxide (NO) [64], which enables vasodilation [11] or reduces mitochondrial oxygen consumption via inhibition of complex I and/or complex IV [4]. This can protect the heart from oxidative stress in hypoxia [11]. In addition, Mb has-suicidal-peroxidase activity [9] and serves as an iron store [5]. A substantial proportion of CHF patients is iron deficient [52]. Also, mice lacking $\mathrm{Mb}\left(\mathrm{myo}^{-/-}\right.$) showed differential gene expression patterns upon induction of isoproterenol-induced heart failure, suggesting a role for $\mathrm{Mb}$ in adaptation to overload [30].

Chronic pressure overload induces extensive myocardial hypertrophy $[6,22,40,53]$, which reduces wall stress, but also decreases mechanical efficiency in hypertrophied rat papillary muscle [65], especially when cardiomyocyte cross-sectional area (CSA) becomes larger than approximately $400-500 \mu \mathrm{m}^{2}$ [65]. Thus, the oxygen demand of hypertrophied myocytes increases several fold, and the extracellular oxygen tension required to prevent hypoxic cores when mitochondria are maximally activated $\left(\mathrm{PO}_{2 \text { crit }}\right)$ may become limiting [6, 40, $53,54]$, also because capillary density is reduced [40, $51,60]$. Hence, a mismatch between oxygen demand and supply arises and either cardiomyocyte hypoxia develops [6, 49, 54] or metabolism must be inhibited [2], which in either case results in reduced energy for contraction and cardiac output.

CSA and oxidative capacity of a muscle are normally under tight control and show a strong inverse relationship that closely fits the Hill-type diffusion model [59]. It is therefore likely that the potential to increase CSA and $\mathrm{VO}_{2 \max }$ simultaneously is limited by oxygen diffusion. Thus, cardiomyocytes can likely sustain greater cell size, increased oxidative capacity and higher workload only when $\mathrm{Mb}$ concentration and/or number of capillaries per myocyte increases $[6,53,59]$. The latter does not occur within 4 weeks in our model of experimental PH [6, 40,51], but we have previously found that a monocrotaline dose of $40 \mathrm{mg} / \mathrm{kg}$ was lethal in rats with a low myoglobin concentration in right-sided cardiomyocytes $(\approx 0.25 \mathrm{mM}[6])$ whereas compensated hypertrophy developed when the concentration of myoglobin was high $(\approx 0.6 \mathrm{mM}[31$, $40])$. The reason why myoglobin concentrations differed between these studies is not known, but could be related to food composition or housing conditions [46]. Increasing the myoglobin concentration in skeletal muscle by iron therapy in iron-deficient $\mathrm{PH}$ patients has some beneficial effects [39].

The mechanisms underlying the regulation of $\mathrm{Mb}$ during hypoxia and increased contractile activity are not yet fully understood [21]. Contractile activity increases $\mathrm{Ca}^{2+}$ levels and thereby activates the calcineurin $(\mathrm{CN})$-nuclear factor of activated T cells (NFAT)/myocyte enhancer factor 2 (MEF2) pathway, which is known to stimulate Mb expression [20] as well as pathological hypertrophy [29]. Also, a progressive increase in $\mathrm{Mb}$ messenger RNA (mRNA) and protein has been demonstrated in rats following thyroid hormone $\mathrm{T}_{3}$ treatment, where Mb levels exceeded euthyroid levels [14]. Type 3 deiodinase (D3) is an inhibitor of $\mathrm{T}_{3}$ activity and is expressed locally in the hypertrophied heart by a hypoxia-inducible factor (HIF)-1 $\alpha$-dependent pathway [49]. The final outcome of these signaling pathways with respect to the $\mathrm{Mb}$ concentration in progressive experimental $\mathrm{PH}$ is a heterogeneous reduction of the myoglobin concentration in right ventricular myocytes [49].

There are several possibilities why the Mb concentration lags behind the rate of cardiomyocyte hypertrophy. First, the capacity of transcription could be the limiting factor in hypertrophied cardiomyocytes, because the volume of cytoplasm per nucleus increases twofold in 2 weeks [6]. However, Ruiter et al. [40] showed that myoglobin mRNA per nucleus increased by a similar factor in stable $\mathrm{PH} 40$ days after the monocrotaline injection but not in progressive PH 35 days after the monocrotaline injection (at a similar degree of hypertrophy), causing a reduced $\mathrm{Mb}$ mRNA concentration in progressive $\mathrm{PH}$ at the time of sacrifice. Furthermore, it may be that the translation of $\mathrm{Mb}$ mRNA is slow or inefficient in progressive PH. It is also possible that increasing ROS production causes $\mathrm{Mb}$ degradation. These data suggest that $\mathrm{Mb}$ mRNA expression is inadequate in progressive HF but also indicate that it can be upregulated in overloaded heart muscle. Hence, the aim of this study was to explore how the $\mathrm{Mb}$ concentration and the oxidative capacity are regulated at an early stage of progressive $\mathrm{PH}$ in concordance with cell size.

We hypothesized that $\mathrm{Mb}$ mRNA expression does increase at an early stage of the development of progressive myocardial hypertrophy. We focused on transcriptional (mRNAs: $\mathrm{Mb}$, peroxisome proliferator-activated receptor gamma coactivator 1-alpha [PGC-1 $\alpha$ ], succinate dehydrogenase [SDH], cytochrome c oxidase [COX], and vascular endothelial growth factor [VEGF]) and translational control of protein synthesis (ribosomal RNA [rRNA], insulin-like growth factor-1Ea [IGF-1Ea], and mechano growth factor [MGF]) and protein degradation (muscle RING-finger protein-1 [MuRF1], muscle atrophy F-box [Mafbx], BCL2/adenovirus E1B $19 \mathrm{kDa}$ interacting protein 3 [BNIP3]) and glycolytic metabolism (glyceraldehyde 3-phosphate dehydrogenase [GAPDH]).

\section{Methods}

\section{Animals and preparations}

The study was approved by the Animal Experimental Committee of the Vrije Universiteit Amsterdam (Amsterdam, The Netherlands) and conformed to the guide of the Dutch Research Council for care and use of laboratory animals. Male Wistar rats $(n=13)$ obtained from Harlan 
(Horst, The Netherlands) were injected subcutaneously with $60 \mathrm{mg} / \mathrm{kg}$ monocrotaline (MCT) at 170-190 g body mass to induce progressive right ventricular HF. This protocol causes a reduction of cardiac output of 25 to $30 \%$ after 3.5 to 4 weeks $[16,65]$. Untreated rats $(n=10)$ were used as controls. All animals received water and standard rat chow (Teklad 2016, Envigo, UK) ad libitum. Three weeks after MCT treatment, rats were anesthetized with halothane and the hearts were rapidly excised and perfused with Tyrode solution $(120 \mathrm{mM}$ $\mathrm{NaCl}, 5 \mathrm{mM} \mathrm{KCl}, 1.2 \mathrm{mM} \mathrm{MgSO}_{4}, 2.0 \mathrm{mM} \mathrm{Na}_{2} \mathrm{HPO}_{4}$, $27 \mathrm{mM} \mathrm{NaHCO}_{3}, 1 \mathrm{mM} \mathrm{CaCl}_{2}, 10 \mathrm{mM}$ glucose and $20 \mathrm{mM}$ 2,3-butanedione monoxime, equilibrated with $95 \% / 5 \% \mathrm{O}_{2} /$ $\mathrm{CO}_{2}$ at $\mathrm{pH} 7.6$ and $10{ }^{\circ} \mathrm{C}$ ) to prevent contraction and to remove blood. Biopsies of the right ventricular wall were embedded in $15 \%(w / v)$ gelatine in Tyrode, $\mathrm{pH} 7.5$, and then frozen in liquid nitrogen. Sections of $5 \mu \mathrm{m}$ thickness were cut and either air dried for $15 \mathrm{~min}$ prior to the determination of $\mathrm{SDH}$ activity (see below) or stored at $-80^{\circ} \mathrm{C}$ for later analysis of the $\mathrm{Mb}$ concentration.

\section{Succinate dehydrogenase histochemistry and determination of cross-sectional area of cardiomyocytes}

SDH activity was measured in the incubation medium (37.5 mM sodium phosphate buffer, $\mathrm{pH}$ 7.6, $75 \mathrm{mM}$ sodium succinate, $5 \mathrm{mM}$ sodium azide, and $0.4 \mathrm{mM}$ tetranitro blue tetrazolium) as previously described [34]. Briefly, sections were incubated in the dark for $7 \mathrm{~min}$ at $37^{\circ} \mathrm{C}[6]$. The spatially averaged absorbance of individual cells in each section was measured at $660 \mathrm{~nm}$ using a calibrated microdensitometer [22] and is expressed as the rate of staining in absorbance units per micrometer section thickness and per second incubation time $\left(\Delta A_{660} \mu \mathrm{m}^{-1} \mathrm{~s}^{-1}\right)$. SDH activity is proportional to $\mathrm{VO}_{2 \max }$ under hyperoxic conditions in vitro $[6,56]$. The measurement included the determination of the CSA of the cell. Absorbance was measured in 20 myocytes, so that a reliable estimate of the mean value was obtained. NIH Image and Image J (http://rsbweb.nih.gov/ij/) were used for analysis-taking the pixel-to-aspect ratio into account.

\section{Myoglobin concentration}

For the determination of $\mathrm{Mb}$ concentration, sections were first fixed in paraformaldehyde vapor and subsequently in $2.5 \%$ glutaraldehyde solution for $10 \mathrm{~min}$ [53]. Sections were then incubated for $1 \mathrm{~h}$ in $59 \mathrm{ml}$ of $50 \mathrm{mM}$ TRIS/ $80 \mathrm{mM} \mathrm{KCl}$ buffer, $\mathrm{pH} 8.0$ which contained $25 \mathrm{mg}$ ortho-tolidine dissolved in $2 \mathrm{ml} 96 \%$ ethanol at $50{ }^{\circ} \mathrm{C}$ and $1.43 \mathrm{ml}$ of $70 \%$ tertiarybutyl-hydroperoxide (Fluka Chemie, Switzerland) [22, 53]. Absorbance was measured at $436 \mathrm{~nm}$ and converted to $\mathrm{Mb}$ concentration using gelatin sections containing known equine $\mathrm{Mb}$ (Sigma, The Netherlands) concentrations.

\section{Calculation of $\mathrm{PO}_{2}$ crit}

An estimate of the minimal extracellular oxygen tension required to prevent hypoxic cell cores when mitochondria are maximally active $\left(\mathrm{PO}_{2}\right.$ crit) of the cardiomyocytes can be calculated as follows [17, 32]:

$\mathrm{PO}_{2 \text { crit }}=\left(\mathrm{VO}_{2 \max } \cdot R^{2}-4 D_{\mathrm{Mb}} \cdot \mathrm{MbO}_{2 \mathrm{R}}\right) / 4 \alpha_{\mathrm{M}} \cdot D_{\mathrm{O} 2}$

where $\mathrm{VO}_{2}$ is the rate of oxygen consumption $\left(\mathrm{mM} \mathrm{s}^{-1}\right), R$ is the radius of the cell, $D_{\mathrm{Mb}}$ is the diffusion coefficient for $\mathrm{Mb}$ in the sarcoplasm, $\alpha_{\mathrm{M}}$ is the solubility of oxygen in the muscle, and $D_{\mathrm{O} 2}$ is the diffusion coefficient for oxygen in muscle tissue. Furthermore, $\mathrm{MbO}_{2 \mathrm{R}}$ depends on $\mathrm{PO}_{2}$ crit, the concentration of oxygenated and deoxygenated $\mathrm{Mb}\left(\mathrm{Mb}_{\text {tot }}\right)$, and the half-saturation pressure of $\mathrm{Mb}\left(P_{50}\right)$ as follows:

$\mathrm{MbO}_{2 \mathrm{R}}=\mathrm{PO}_{2 \text { crit }} \cdot \mathrm{Mb}_{\text {tot }} /\left(\mathrm{PO}_{2 \text { crit }}+P_{50}\right)$

Substitution of the latter into the first equation allowed the calculation of $\mathrm{PO}_{2}$ crit as a function of parameters that were measured or estimated using calibrated histochemistry [53] or obtained from literature (see below).

To estimate $\mathrm{PO}_{2 \text { crit }}$ at $\mathrm{VO}_{2 \max }, \mathrm{VO}_{2 \max }$ was estimated from measured SDH values based on previous observations that showed SDH activity to be proportional to $\mathrm{VO}_{2 \max }$ with a staining rate of $1 \cdot 10^{-4} \Delta A_{660} \mu^{-1} \mathrm{~s}^{-1}$ corresponding to a $\mathrm{VO}_{2 \max }$ of $0.6 \mathrm{mM} \mathrm{s}^{-1}[6,56]$. The concentration of $\mathrm{Mb}$ was determined from the heart sections as described above. All other values were obtained from literature: $D_{\mathrm{Mb}}=0.27$. $10^{-4} \mathrm{~mm}^{2} \mathrm{~s}^{-1}$ [3], $\alpha_{\mathrm{m}} \cdot \mathrm{DO}_{2}=2 \mathrm{nM} \mathrm{mm}^{-2} \mathrm{~s}^{-1} \mathrm{mmHg}^{-1}$ [55], and $P_{50}=6.5 \mathrm{mmHg}[8,13,45]$. Note that this calculation provides an underestimate of $\mathrm{PO}_{2 \text { crit }}$ because zero-order kinetics for mitochondrial oxygen consumption and equilibrium of the reaction of myoglobin with oxygen are assumed (see [41] and [7], respectively, for discussion).

\section{Quantitative polymerase chain reaction (qPCR)}

Parts (mean mass $68.8 \pm 8.24 \mathrm{mg}$ ) of the right ventricular free wall were weighed while frozen. Total RNA was extracted using a RiboPure kit (Applied Biosystems, Carlsbad, CA) according to the manufacturer's instructions.

Real-time PCR was performed using a StepOne Real-Time PCR system (Applied Biosystems) to determine mRNA expression levels. From each muscle, 500 ng total RNA was reverse transcribed using an RNA-to-cDNA kit (Applied Biosystems). For each gene target, $5 \mu$ of the reverse transcribed reaction product was amplified using Fast SYBR Green Mastermix (Applied Biosystems). The primers used are listed in Table 1.

Mean cycle thresholds were converted to relative expressions by subtracting the $18 \mathrm{~S}$ rRNA cycle threshold and determining $2^{-\Delta \mathrm{C} t}$. Expressions relative to $18 \mathrm{~S}$ rRNA were 
Table 1 Overview of primers used for RT-PCR

\begin{tabular}{lll}
\hline Gene & Forward $\left(5^{\prime}-3^{\prime}\right)$ & Reverse $\left(3^{\prime}-5^{\prime}\right)$ \\
\hline 18 S & CGAACGTCTGCCCTATCAACTT & ACCCGTGGTCACCATGGTA \\
Myoglobin & CCGGTCAAGTACCTGGAGTTTA & TCCCCGGAATATCTCTTCTTC \\
VEGF & CTGCTGTGGACTTGAGTTGG & AAGACCACACCGGAGTCTTT \\
IGF-1Ea & AAGCCTACAAAGTCAGCTCG & TCAAGTGTACTTCCTTCTGAGTC \\
MGF & CAAGACTCAGAAGTCCCAGC & AAGTGTACTTCCTTTCCTTCTC \\
MuRF1 & TGCCCCCTTACAAAGCATCTT & CAGCATGGAGATGCAATTGC \\
Mafbx & TGAAGACCGGCTACTGTGGAA & CGGATCTGCCGCTCTGA \\
BNIP3 & GTCACTTCCCAGGCCTGTCGC & TACCCAGGAGCCCTGCAGGTTCT \\
GAPDH & TGGCCTCCAAGGAGTAAGAAAC & GGCCTCTCTCTTGCTCTCAGTATC \\
PGC-1 $\alpha$ & ATGAGAAGCGGGAGTCTGAA & GCGCTCTTCAATTGCTTTCT \\
SDH & CAGAGAAGGGATCTGTGGCT & TGTTGCCTCCGTTGATGTTC \\
COX1 & TGCCAGTATTAGCAGCAGGT & GAATTGGGTCTCCACCTCCA \\
COX4 & AGTCCAATTGTACCGCATCC & ACTCATTGGTGCCCTTGTTC \\
\hline
\end{tabular}

BNIP3 BCL2/adenovirus E1B $19 \mathrm{kDa}$ interacting protein 3, COX cytochrome c oxidase, GAPDH glyceraldehyde 3-phosphate dehydrogenase, $I G F$ insulin-like growth factor, $M a f b x$ muscle atrophy F-box, $M G F$ mechano growth factor, $M u R F 1$ muscle RING-finger protein-1, $P G C$ - $1 \alpha$ peroxisome proliferator-activated receptor gamma coactivator 1-alpha, $S D H$ succinate dehydrogenase, $V E G F$ vascular endothelial growth factor multiplied by total RNA per milligram of heart tissue to obtain mRNA concentrations. By multiplying the concentration by the mean CSA of the cardiomyocytes, expression levels of the genes per nucleus were determined. This normalization is based on the observations that the number of myocyte nuclei does not change during the development of hypertrophy [54] and that myocyte length does not change [57]. In this case, the volume of cytoplasm per nucleus is proportional to myocyte CSA and thus normalization for CSA reflects changes in gene expression per nucleus. It should be noted that the expression per nucleus is therefore not an absolute value but rather a relative measure.

\section{Statistical analysis}

Independent $t$ tests were used to compare measurements from MCT-treated animals with those of the control animals. Equality of variance was tested using Levene's test and corrected if significant. Normality was tested using the Shapiro-Wilk test. For data with a non-normal distribution, the Mann-Whitney $U$ test was used. Values are given as mean \pm standard error of the mean (SEM) unless stated otherwise; $p<0.05$ was considered statistically significant.

\section{Results and discussion}

\section{Effects of MCT on cardiomyocyte phenotype}

Figure 1 shows lung mass and RV myocyte CSA against body mass, CSA against lung mass, and CSA, SDH activity, and $\mathrm{Mb}$ concentration both for $\mathrm{PH}$ rats and controls. Lung mass and CSA were higher in MCTtreated rats although body mass was lower (Fig. 1a-c) illustrating the detrimental effects of the MCT injection after 21 days.

Cardiomyocyte CSA of MCT rats thus increased 1.8-fold compared to that of controls ( $p<0.001$; Fig. $1 \mathrm{~d}-\mathrm{f}$ ), confirming hypertrophy. Based on the hyperbolic inverse relationship between muscle fiber size and oxidative capacity [56, 59], we expected to see a decrease in oxidative capacity during hypertrophy. However, SDH activity was similar in $\mathrm{PH}$ rats and controls ( $p=0.34$; Fig. $1 \mathrm{~d}$, e, and $\mathrm{g}$ ), indicating that oxidative capacity per unit volume of cytoplasm was retained after MCT injection. Since CSA was increased, the total oxidative capacity per cardiomyocyte increased. As this is accompanied by higher oxygen consumption per cardiomyocyte, these hypertrophied cells would require increased $\mathrm{Mb}$ concentrations to prevent hypoxia. However, $\mathrm{Mb}$ concentrations in $\mathrm{PH}$ and control samples were not statistically different ( $p=0.11$; Fig. $1 \mathrm{~h}-\mathrm{j}$ ).

The increase in absolute oxidative capacity without a concomitant increase in $\mathrm{Mb}$ protein concentration led to a $\mathrm{PO}_{2 \text { crit }}$ in $\mathrm{PH}(7.7 \mathrm{mmHg})$ that was over twofold greater than the $\mathrm{PO}_{2 \text { crit }}(3.4 \mathrm{mmHg})$ in controls $(p<0.001$; Fig. $1 \mathrm{k})$. The increase in $\mathrm{PO}_{2 \text { crit }}$ and the decrease in the capillary density [40, $51,60]$ are likely to cause core hypoxia in cardiomyocytes at the maximum heart rate [54].

The $\mathrm{Mb}$ concentrations in the present study are different from those previously reported $[6,22,53]$. This variation indicates that $\mathrm{Mb}$ regulation in MCT-induced $\mathrm{PH}$ is complicated. The $\mathrm{Mb}$ concentration was previously shown to be decreased in experimental $\mathrm{PH}$ [40] after 4 weeks, suggesting that the decrease occurs during the fourth week, when the cardiomyocytes no longer increase in size [6]. 

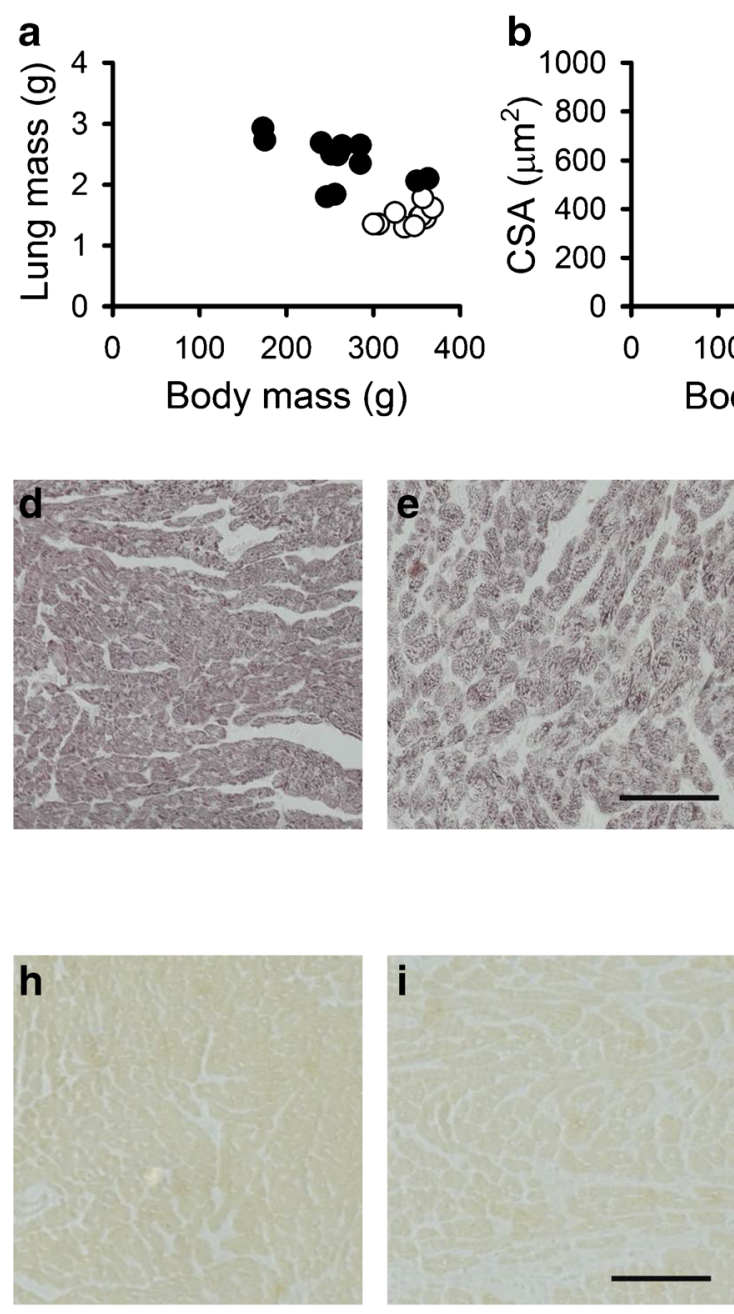

Fig. 1 Effects of monocrotaline-induced pulmonary hypertension on phenotypic characteristics of the rats and cardiomyocytes in rat right ventricle. Lung mass (a) and myocyte CSA (b) are plotted against body mass, and myocyte CSA is plotted against lung mass (c). Representative examples of control and $\mathrm{PH}$ right ventricular cardiomyocytes stained for succinate dehydrogenase $(\mathrm{SDH})$ activity $(\mathbf{d}, \mathbf{e})$ and myoglobin $(\mathbf{h}, \mathbf{i})$ are

\section{Effects of MCT on total RNA content in the right ventricle}

The volume of cytoplasm each nucleus had to maintain (i.e., the myonuclear domain) increased with CSA. Thus, to maintain SDH activity and $\mathrm{Mb}$ concentration, either the rate of transcription/translation or both should have been enhanced and/or the half-life of $\mathrm{Mb}$ should have increased. Because 80 $85 \%$ of all RNA within muscle cells consists of rRNA [28], we first assessed total RNA content per milligram heart tissue, as a measure of translational capacity.

Total RNA was proportional to wet weight (Fig. 2a; $p<0.001)$. However, the relationship differed between $\mathrm{PH}$ rats and controls, indicating that rats with $\mathrm{PH}$ had $32 \%$ higher total RNA levels per milligram muscle tissue $(p=0.001)$. Total RNA per nucleus was 2.7 times higher
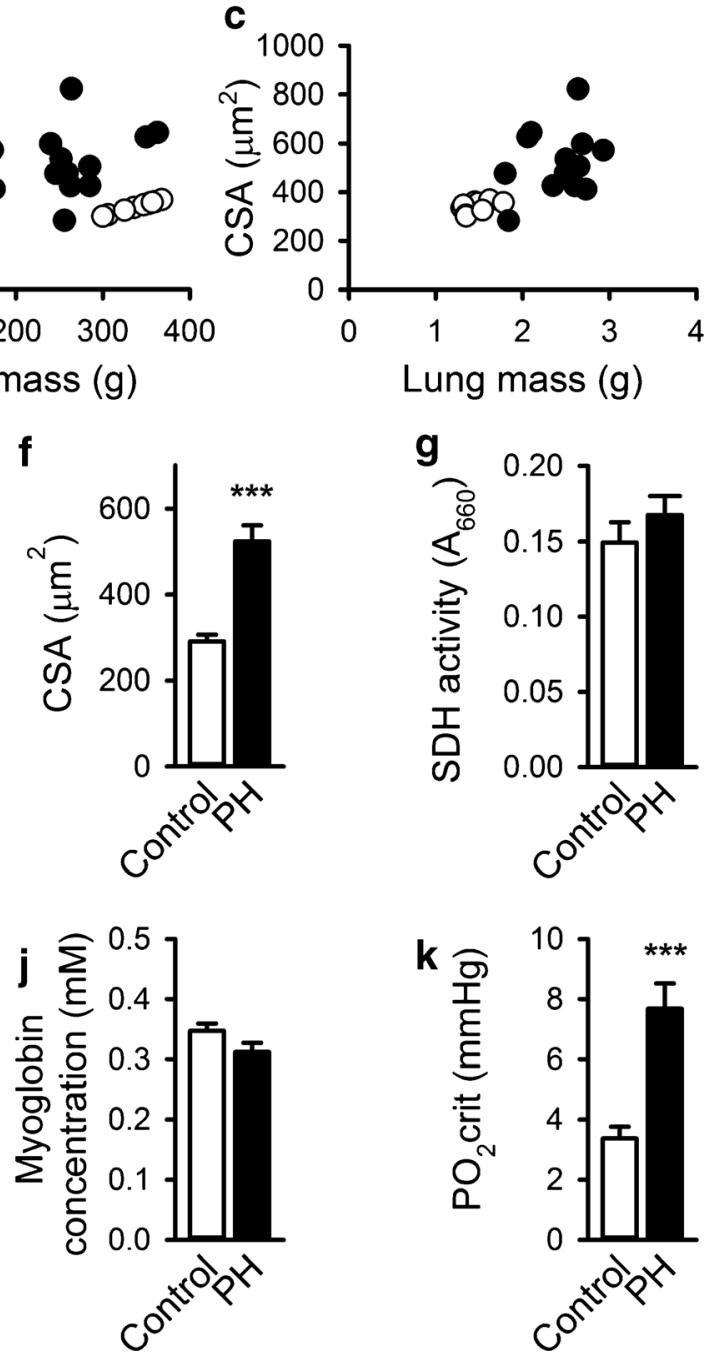

shown. MCT-induced heart failure caused hypertrophy of cardiomyocytes, as illustrated by an increase in cellular cross-sectional area (CSA) (f). Nevertheless, SDH activity (g) and myoglobin protein concentration $(\mathbf{h}-\mathbf{j})$ both remained constant. Therefore, $\mathrm{PO}_{2 \text { crit }}$ was increased in $\mathrm{PH}(\mathbf{k}) . * * * p<0.001$. White bars/circles: control group, black bars/circles: PH. Scale bar indicates $100 \mu \mathrm{m}$

in $\mathrm{PH}$ rats compared to controls ( $p<0.001$; Fig. 2b). Expression levels of 18S rRNA relative to total RNA were similar ( $p=0.96$; Fig. $2 c$ ). On the basis of these results, we conclude that rRNA content was proportional to the increase in total RNA, reflecting a higher overall translational capacity in $\mathrm{PH}$ cardiomyocytes. Hence, it is unlikely that a limitation in the translational capacity impaired the increase in $\mathrm{Mb}$ protein expression.

The increase in total RNA and the absolute increase of $18 \mathrm{~S}$ rRNA expression levels in PH rats also indicate that mRNA expression levels normalized to $18 \mathrm{~S}$ rRNA lead to an underestimation of the mRNA expression levels in $\mathrm{PH}$ rats compared to controls. Therefore, we normalized subsequent mRNA expression levels both as cardiac tissue mRNA concentration and as amount per nucleus. 

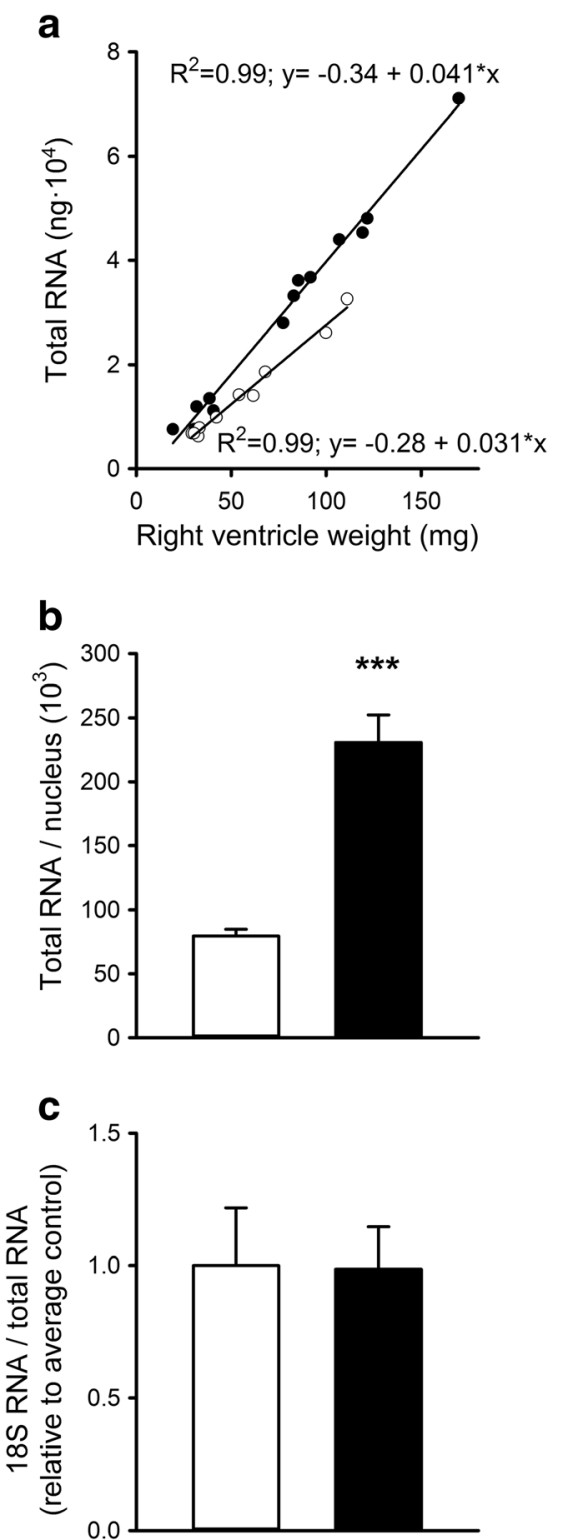

Fig. 2 Effects of monocrotaline-induced pulmonary hypertension on total RNA content and $18 \mathrm{~S}$ rRNA in rat right ventricle. The amount of total RNA was proportional to the weight of the right ventricle, although the relationship is different for $\mathrm{PH}$ rats versus controls (a). The mean amount of total RNA per nucleus was more than twofold greater for the $\mathrm{PH}$ group compared to controls (b). Nevertheless, the expression of $18 \mathrm{~S}$ rRNA relative to total RNA was similar in both groups $(\mathbf{c}) . * * * p<0.001$, $* * p<0.01$. White bars/circles: control, black bars/circles: $\mathrm{PH}$

\section{Effects of MCT on transcription of regulators of protein synthesis and degradation}

We studied mRNA expression levels of several factors related to protein synthesis and degradation as shown in Fig. 3.

In order to explain the lack of increase in $\mathrm{Mb}$ concentrations, we considered IGF-1Ea and its splice variant MGF, which are known to activate both the rate of transcription and translation [15] and repress several mediators of degradation [43]. In response to exercise or overload, IGF-1 acts as an autocrine/

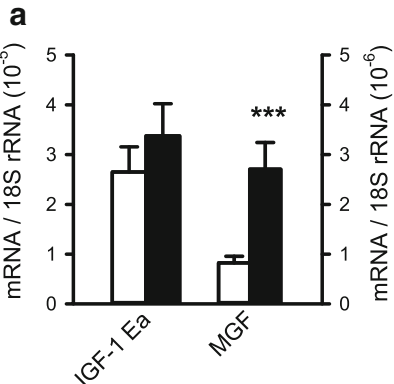

d
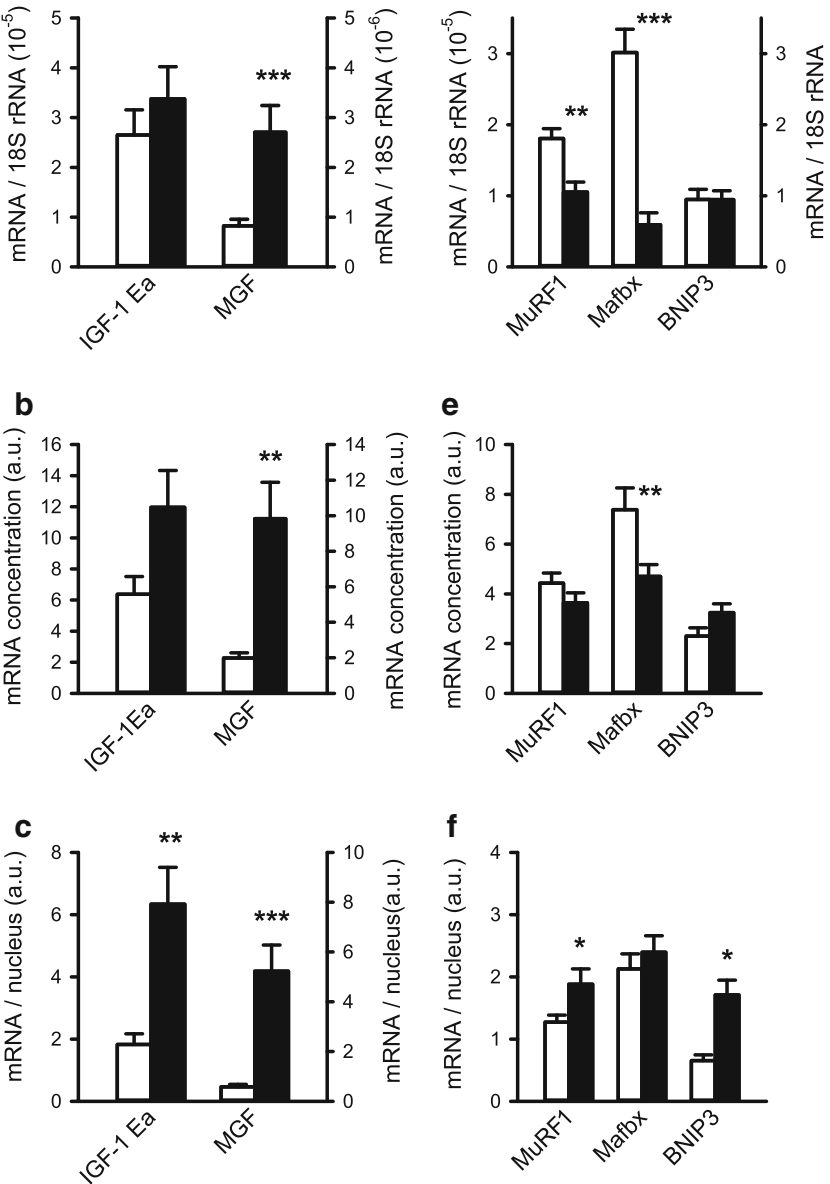

Fig. 3 Effects of monocrotaline-induced pulmonary hypertension in rat on expression of regulators of protein synthesis and degradation in the right ventricle. Expression levels of insulin-like growth factor (IGF)-1Ea and mechano growth factor (MGF) mRNA are presented relative to $18 \mathrm{~S}$ (a), as concentration per milligram heart tissue (b) or per nucleus (c). Expression levels of muscle RING-finger protein-1 (MuRF1), muscle atrophy F-box (Mafbx), and BCL2/adenovirus E1B $19 \mathrm{kDa}$ interacting protein 3 (BNIP3) were analyzed as markers of degradation and shown relative to $18 \mathrm{~S}(\mathbf{d})$, as concentration (e) and per nucleus (f). Note that the right axis in $\mathbf{d}$ applies only to BNIP3 expression levels. ${ }^{* * *} p<0.001$, $* * p<0.01, * p<0.05$. White bars: control, black bars: $\mathrm{PH}$

paracrine factor to induce hypertrophy in left ventricular myocardium of rats [42] and humans [47]. It has been shown that physiologic and pathologic cardiac hypertrophy are mediated by different pathways whereby IGF-1 is essential for physiologic hypertrophy and acts via the phosphatidylinositol 3kinase (PI3K)-Akt-mammalian target of rapamycin (mTOR) pathway whereas pathologic hypertrophy is mediated by the $\mathrm{Ca}^{2+}$-CN-NFAT pathway (see [61] for review).

Relative to 18S rRNA expression levels and expressed as concentration (i.e., per milligram tissue), IGF-1Ea expression levels did not differ significantly between the two groups ( $p=0.41, p=0.07$; Fig. 3a, b). However, expression levels of mRNA per nucleus increased 3.5-fold in $\mathrm{PH}$ rats compared to controls $(p<0.01$; Fig. $3 \mathrm{c})$. MGF expression levels 
were also increased, irrespective of whether they were expressed relative to $18 \mathrm{~S}(p<0.001)$, concentration $(p<0.01)$, or per nucleus $(p<0.001$; Fig. 3a-c). In addition to the activation of mRNA transcription and translation, MGF has been shown to preserve cardiac function by inhibiting apoptotic pathways in the myocardium and preventing pathologic cardiac hypertrophy [27].

As expression of IGF-1Ea and MGF mRNA per nucleus were both increased, it is conceivable that the rates of transcription and translation were increased. To investigate this further, we assessed several markers of protein degradation. MuRF1 and Mafbx are known to regulate contractile protein degradation, thereby preventing massive hypertrophy in skeletal and cardiac muscle cells [25, 62]. Furthermore, BNIP3 induces mitochondrial dysfunction and autophagy [36] and apoptosis under hypoxic conditions [38]. Since SDH protein expression was unexpectedly increased, we also studied BNIP3 mRNA expression levels.

The expression levels of MuRF1, Mafbx, and BNIP3 were lower or unaltered in $\mathrm{PH}$ rats versus controls when expressed relative to $18 \mathrm{~S}$ rRNA $(p<0.01, p<0.001$, and $p=0.99$, respectively; Fig. 3d), whereas an increase was shown in the expression per nucleus for MuRF1 and BNIP3 (both $p<0.05$ ) by 1.5 - and 2.6-fold, respectively (Fig. 3f). This appeared to be sufficient to keep the concentration constant, whereas the concentration of Mafbx was rather decreased $(p<0.01)$ due to the constant expression per nucleus (Fig. 3e). Together, these results show a clear elevation in the mRNA concentration of growth factors involved in protein synthesis. By contrast, the concentration of E3 ligases was lower or remained constant. The increase in translational machinery and signaling was apparently sufficient to maintain but not to increase the $\mathrm{Mb}$ concentration.

\section{Effects of MCT on transcriptional expression of metabolic enzymes}

GAPDH catalyzes the conversion of glyceraldehyde 3phosphate to D-glycerate 1,3-bisphosphate and is a marker of glycolytic metabolism. Expression levels of GAPDH did not differ between the two groups when expressed relative to $18 \mathrm{~S}$ rRNA or as mRNA concentration (Fig. 4a, b). When considered per nucleus, GAPDH mRNA expression levels were 2.5fold higher in PH rats compared to control $(p<0.05$; Fig. $4 c)$. Because the mRNA concentration does not decrease and the rRNA increases, this result suggests an increase of the glycolytic capacity in MCT-induced PH. A shift towards glycolytic metabolism was also observed in myo $^{-/}$mice suggesting compensation for the lack of $\mathrm{Mb}$ [10]. However, Mb concentrations in the present study remained constant and thus do not explain the supposed increase in glycolytic capacity. Alternatively, a shift towards glycolytic metabolism that was associated with a transition towards a decompensated state in
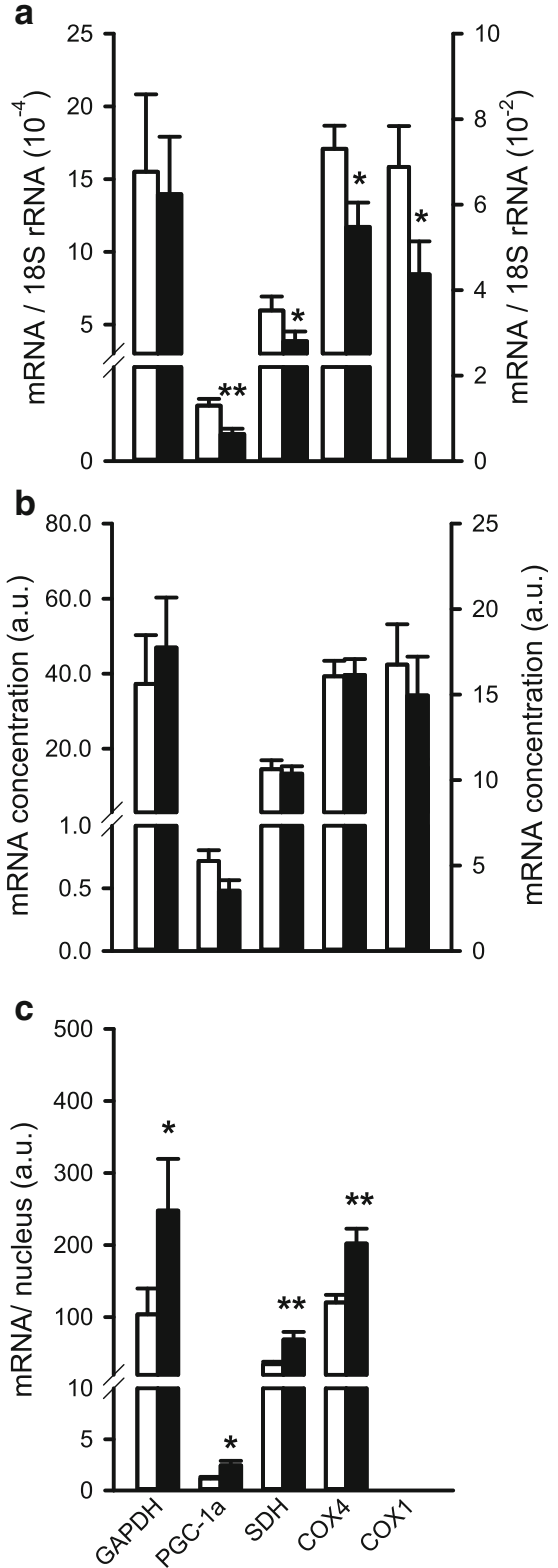

Fig. 4 Effects of monocrotaline-induced pulmonary hypertension on expression of metabolic markers in rat right ventricle. Expression levels of glyceraldehyde 3-phosphate dehydrogenase (GAPDH), peroxisome proliferator-activated receptor gamma coactivator 1-alpha (PGC-1 $\alpha$ ), succinate dehydrogenase (SDH), cytochrome c oxidase (COX) 4 , and COX1 are shown relative to $18 \mathrm{~S}$ (a), as concentration (b) and per nucleus (c). Note that the right axis in a and b only applies to COX1. COX1 expression levels per nucleus are not presented because this subunit is encoded by the mitochondrial DNA. $* * * p<0.001$, ${ }^{* *} p<0.01, * p<0.05$. White bars: control, black bars: $\mathrm{PH}$

PH [51] may have accounted for the increased glycolytic capacity as shown here. Regardless of the underlying mechanism, this shift may reflect one way to lower oxygen utilization of the cardiac myocytes.

We investigated whether SDH mRNA expression levels were increased. Expressed relative to $18 \mathrm{~S}$ rRNA, we observed a decrease in $\mathrm{PH}$ rats compared to controls $(p<0.05$; Fig. 4a) 
while mRNA concentration remained constant (Fig. 4b). By contrast, the expression per nucleus was almost twice as high in PH rats versus controls ( $p<0.01$; Fig. $4 \mathrm{c}$ ). Because cardiomyocyte CSA and SDH activity both increased almost twofold in PH rats versus controls, it can be concluded that SDH mRNA expression was sufficient and in line with the increase in SDH activity per myocyte.

SDH and COX activities have been shown to be proportional during the development of MCT-induced PH [31]. To confirm that SDH activity reflected the oxidative capacity, we also measured mRNA expression levels of both COX1 and COX4, subunits of cytochrome c oxidase. Although expression levels of both were decreased relative to $18 \mathrm{~S}(p<0.05$; Fig. $4 \mathrm{a})$, the mRNA concentrations remained constant (Fig. 4b). The expression of COX4 mRNA per nucleus was increased almost twofold, in line with the SDH activity (Fig. 4c). Expression per nucleus is not shown for COX1 because this subunit is encoded by the mitochondrial DNA [12]. However, the observed increase in COX4 expression per nucleus, together with the constant COX1 mRNA concentration despite the increase in cell size, indicates that expression levels of both subunits were proportional to SDH activity and were not limiting the increased oxidative capacity. Therefore, $\mathrm{SDH}$ activity seems an appropriate estimate of $\mathrm{VO}_{2 \max }$ used to estimate $\mathrm{PO}_{2}$ crit.

We also investigated how SDH activity was maintained despite substantial hypertrophy. PGC- $1 \alpha$ is known to be the master regulator of mitochondrial biosynthesis [23, 35]. Following hypoxia, its expression is increased or PGC- $1 \alpha$ is activated because of an increase in ROS production, p38 mitogen-activated protein kinase (MAPK) and AMPactivated protein kinase (AMPK) levels [18, 48]. However, although we show that expression levels relative to that of $18 \mathrm{~S}$ rRNA were lower $(p<0.01$; Fig. $4 \mathrm{a})$, the expression per nucleus was over twofold higher in $\mathrm{PH}$ rats versus controls (Fig. 4c), and there was no difference in PGC- $1 \alpha$ mRNA concentrations between the two groups (Fig. 4c).

We conclude that the upregulation of PGC- $1 \alpha$ per nucleus is probably the reason why the oxidative capacity was maintained. We observed that cardiomyocyte hypertrophy with maintained SDH activity requires an increase in interstitial $\mathrm{PO}_{2 \text { crit. }}$ This implies that in order to make use of all mitochondrial enzyme activity, oxygen supply to the cardiomyocytes needs to be increased.

\section{Effects of MCT on transcriptional regulation of proteins involved in oxygen supply or the regulation thereof}

To explain the lack of increase in $\mathrm{Mb}$ concentration, we assessed both $\mathrm{Mb}$ and VEGF mRNA expression levels, as these are indicative of changes in oxygen supply. In addition to its role in angiogenesis [24], it is suggested that VEGF can directly stimulate $\mathrm{Mb}$ mRNA transcription via a currently unknown mechanism [58]. An increase of VEGF expression could be either the result of enhanced expression or activation of PGC-1 $\alpha$ [1] or resulting from stabilization of HIF-1 $\alpha$ [48]. It is known that HIF- $1 \alpha$ promotes VEGF-induced angiogenesis under hypoxic conditions [44]. Although we did not measure HIF- $1 \alpha$, it is reported to accumulate consistently in $\mathrm{PH}$ $[6,37,49,51,54]$. No differences in VEGF mRNA expression levels relative to $18 \mathrm{~S}$ rRNA were observed (Fig. 5a), and although the expression levels per nucleus were increased in $\mathrm{PH}$ rats compared to controls ( $p<0.001 ;$ Fig. $5 \mathrm{c}$ ), there was no difference between the groups in the VEGF mRNA concentration (Fig. 5b). These findings are consistent with previous reports that VEGF protein expression remains constant both in stable and progressive HF in rats after 3 weeks of right ventricular overload [40].

Although a decrease was seen in the expression relative to 18S RNA $(p<0.001)$ and mRNA concentration $(p<0.01$; Fig. $5 \mathrm{a}, \mathrm{b}$ ), the expression of $\mathrm{Mb}$ mRNA per nucleus remained constant in $\mathrm{PH}$ rats (Fig. 5c). In order to retain a stable $\mathrm{Mb}$ protein concentration with the increased cell size, we had expected to find a higher expression of $\mathrm{Mb}$ mRNA per nucleus. Our data suggest that the $\mathrm{Mb}$ protein concentration was maintained due to an increase in the rate of translation, rather than by an increased rate of transcription. It should be noted that we did not correct for an increase in interstitial space from $11 \%$ in controls to $17 \%$ in PH rats [40]. However, such a correction would only slightly increase the calculated concentration of $\mathrm{Mb}$ mRNA per milligram right ventricle tissue by $12-21 \%$, but expression levels per nucleus would remain unaltered. This extends results of Ruiter et al. [40] who showed that myoglobin mRNA was also not upregulated at later stages of progressive $\mathrm{PH}$, whereas it was upregulated in compensated PH. Furthermore, after 2 weeks of isoproterenol-induced cardiac hypertrophy, Mb mRNA expression was shown to be constant [30]. However, this was expressed relative to a certain amount of RNA. Since we have shown here that total RNA increased in MCT-induced cardiac hypertrophy, this may also be the case for isoproterenol-induced cardiac hypertrophy and would increase Mb mRNA concentrations in diseased mice. Further research is needed to reveal whether $\mathrm{Mb}$ mRNA is only upregulated at even earlier onset of heart failure or whether $\mathrm{Mb}$ mRNA expression levels are differentially altered in the different models. Thus, our hypothesis is rejected and the question remains why Mb mRNA expression was not upregulated at an early stage of progressive PH. One explanation for this surprising result is that oxidative metabolism was inhibited in progressive $\mathrm{PH}$ [2], thereby preventing the hypoxia stimulus required for myoglobin expression, while myocytes are able to adapt to hypoxia by increasing myoglobin expression in compensated $\mathrm{PH}$.

Previous studies have demonstrated regulation of $\mathrm{Mb}$ via $\mathrm{Ca}^{2+}{ }^{2+} \mathrm{CN}-\mathrm{NFAT} / \mathrm{MEF} 2$ pathways [29] indicating that contractile activity may contribute to the regulation of $\mathrm{Mb}$ expression. 

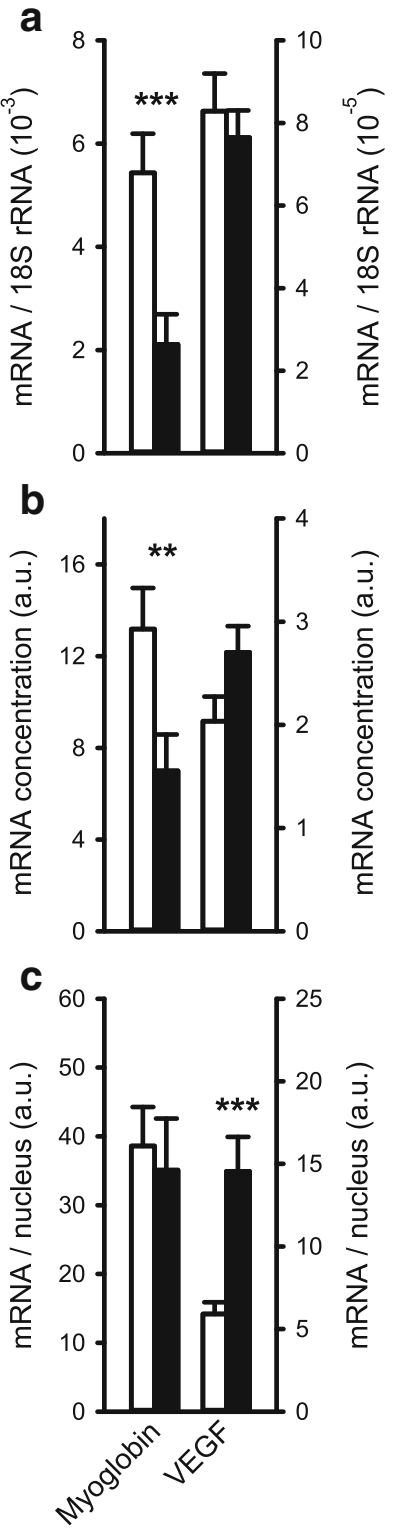

Fig. 5 Effects of monocrotaline-induced pulmonary hypertension on mRNA expression levels of myoglobin and vascular endothelial growth factor in rat right ventricle. Expression levels of myoglobin $(\mathrm{Mb})$ and vascular endothelial growth factor (VEGF) are presented for both the $\mathrm{PH}$ group and controls relative to $18 \mathrm{~S}$ (a), as concentration (b) or per nucleus (c). $* * * p<0.001, * * p<0.01, * p<0.05$. White bars: control, black bars: $\mathrm{PH}$

Furthermore, it has been demonstrated that hypoxia in combination with contractile activity enhances $\mathrm{Mb}$ expression in $\mathrm{C}_{2} \mathrm{C}_{12}$ myotubes, mouse skeletal [20] and heart [26] muscle, and zebrafish high oxidative muscles [19]. However, this was not the case in our MCT-induced overload of the cardiomyocytes of the right ventricle, despite the fact that increased power output and reduced oxygen tension (judging from increased HIF- $1 \alpha$ expression $[6,37,49,51,54])$ were likely present. However, $\mathrm{Mb}$ expression was increased following lipid supplementation in hypoxic $\mathrm{C}_{2} \mathrm{C}_{12}$ cells and rat soleus muscle, independent of $\mathrm{CN}$ signaling, suggesting that other pathways for $\mathrm{Mb}$ expression do exist [46]. Furthermore, as mentioned before, iron supplementation [39] and treatment with thyroid hormone $[14,22]$ both successfully increased $\mathrm{Mb}$ expression in $\mathrm{PH}$ patients and rat, respectively, and thus may serve as required additional stimuli.

In conclusion, this study shows that $\mathrm{Mb}$ mRNA expression was not sufficient to increase $\mathrm{Mb}$ protein concentrations even at an early stage of progressive PH. Upregulating Mb mRNA expression, e.g., by supplementation of iron [39] and fatty acid [46] and/or stimulation of the thyroid hormone receptor [14], is therefore a promising therapeutic strategy. Further research should reveal the optimal combination of hypoxia, load, and dietary status to increase $\mathrm{Mb}$ mRNA and protein levels in chronic heart failure.

Compliance with ethical standards All applicable international, national, and/or institutional guidelines for the care and use of animals were followed. All procedures performed in studies involving animals were in accordance with the ethical standards of the Vrije Universiteit, Amsterdam, The Netherlands.

Conflict of interest The authors declare that they have no conflict of interest.

Open Access This article is distributed under the terms of the Creative Commons Attribution 4.0 International License (http:// creativecommons.org/licenses/by/4.0/), which permits unrestricted use, distribution, and reproduction in any medium, provided you give appropriate credit to the original author(s) and the source, provide a link to the Creative Commons license, and indicate if changes were made.

\section{References}

1. Arany Z, Foo SY, Ma Y, Ruas JL, Bommi-Reddy A, Girnun G, Cooper M, Laznik D, Chinsomboon J, Rangwala SM, Baek KH, Rosenzweig A, Spiegelman BM (2008) HIF-independent regulation of VEGF and angiogenesis by the transcriptional coactivator PGC-1alpha. Nature 451:1008-1012. doi:10.1038 /nature06613

2. Balestra GM, Mik EG, Eerbeek O, Specht P, van der Laarse WJ, Zuurbier CJ (2015) Increased in vivo mitochondrial oxygenation with right ventricular failure induced by pulmonary arterial hypertension: mitochondrial inhibition as driver of cardiac failure? Respir Res 16:6. doi:10.1186/s12931-015-0178-6

3. Baylor SM, Pape PC (1988) Measurement of myoglobin diffusivity in the myoplasm of frog skeletal muscle fibres. J Physiol 406:247275. doi:10.1113/jphysiol.1988.sp017379

4. Clementi E, Brown GC, Feelisch M, Moncada S (1998) Persistent inhibition of cell respiration by nitric oxide: crucial role of S-nitrosylation of mitochondrial complex I and protective action of glutathione. Proc Natl Acad Sci U S A 95:76317636

5. Dallman PR, Schwartz HC (1965) Distribution of cytochrome C and myoglobin in rats with dietary iron deficiency. Pediatrics 35: 677-686. doi:10.1172/JCI105269

6. des Tombe AL, van Beek-Harmsen BJ, Lee-de Groot MBE, Van der Laarse WJ (2002) Calibrated histochemistry applied to oxygen 
supply and demand in hypertrophied rat myocardium. Microsc Res Tech 58:412-420. doi:10.1002/jemt.10153

7. Endeward V (2012) The rate of the deoxygenation reaction limits myoglobin- and hemoglobin-facilitated $\mathrm{O}(2)$ diffusion in cells. $\mathrm{J}$ Appl Physiol 112:1466-1473. doi:10.1152/japplphysiol.00835.2011

8. Enoki Y, Matsumura K, Ohga Y, Kohzuki H, Hattori M (1995) Oxygen affinities (P50) of myoglobins from four vertebrate species (Canis familiaris, Rattus norvegicus, Mus musculus and Gallus domesticus) as determined by a kinetic and an equilibrium method. Comp Biochem Physiol B Biochem Mol Biol 110:193-199. doi:10.1016/0305-0491(94)00119-F

9. Flögel U, Godecke A, Klotz LO, Schrader J (2004) Role of myoglobin in the antioxidant defense of the heart. FASEB 18:11561158. doi:10.1096/fj.03-1382fje

10. Flögel U, Laussmann T, Godecke A, Abanador N, Schafers M, Fingas CD, Metzger S, Levkau B, Jacoby C, Schrader J (2005) Lack of myoglobin causes a switch in cardiac substrate selection. Circ Res 96:e68-e75. doi:10.1161/01.RES.0000165481.36288.d2

11. Flögel U, Merx MW, Godecke A, Decking UK, Schrader J (2001) Myoglobin: a scavenger of bioactive NO. Proc Natl Acad Sci U S A 98:735-740. doi:10.1073/pnas.011460298

12. Garnier A, Fortin D, Deloménie C, Momken I, Veksler V, VenturaClapier R (2003) Depressed mitochondrial transcription factors and oxidative capacity in rat failing cardiac and skeletal muscles. J Physiol 551:491-501. doi:10.1113/jphysiol.2003.045104

13. Gayeski TE, Honig CR (1991) Intracellular PO2 in individual cardiac myocytes in dogs, cats, rabbits, ferrets, and rats. Am J Phys 260:H522-H53

14. Giannocco G, DosSantos RA, Nunes MT (2004) Thyroid hormone stimulates myoglobin gene expression in rat cardiac muscle. Mol Cell Endocrinol 226:19-26. doi:10.1016/j. mce.2004.07.007

15. Goldspink G, Yang SY (2004) The splicing of the IGF-I gene to yield different muscle growth factors. In: Advances in Genetics. Academic Press, San Diego, p 23-49

16. Handoko ML, de Man FS, Happé CM, Schalij I, Musters RJ, Westerhof N, Postmus PE, Paulus WJ, van der Laarse WJ, VonkNoordegraaf A (2009) Opposite effects of training in rats with stable and progressive pulmonary hypertension. Circulation 120: 42-49. doi:10.1161/circulationaha.108.829713

17. Hill AV (1965) Trials and trails in physiology. Edward Arnold, London

18. Jager S, Handschin C, St-Pierre J, Spiegelman BM (2007) AMPactivated protein kinase (AMPK) action in skeletal muscle via direct phosphorylation of PGC-1alpha. Proc Natl Acad Sci U S A 104:12017-12022. doi:10.1073/pnas.0705070104

19. Jaspers RT, Testerink J, Della Gaspera B, Chanoine C, Bagowski CP, van der Laarse WJ (2014) Increased oxidative metabolism and myoglobin expression in zebrafish muscle during chronic hypoxia. Biology open 3:718-727. doi:10.1242/bio.20149167

20. Kanatous SB, Mammen PP, Rosenberg PB, Martin CM, White MD, Dimaio JM, Huang G, Muallem S, Garry DJ (2009) Hypoxia reprograms calcium signaling and regulates myoglobin expression. Am J Physiol Cell Physiol 296:C393-C402. doi:10.1152/ajpcell.00428.2008

21. Kanatous SB, Mammen PPA (2010) Regulation of myoglobin expression. J Exp Biol 213:2741-2747. doi:10.1242/jeb.041442

22. Lee-de Groot MBE, des Tombe AL, Van der Laarse WJ (1998) Calibrated histochemistry of myoglobin concentration in cardiomyocytes. J Histochem Cytochem 46:1077-1084. doi: $10.1177 / 002215549804600912$

23. Lehman JJ, Barger PM, Kovacs A, Saffitz JE, Medeiros DM, Kelly DP (2000) Peroxisome proliferator-activated receptor gamma coactivator-1 promotes cardiac mitochondrial biogenesis. J Clin Invest 106:847-856. doi:10.1172/JCI10268
24. Leung DW, Cachianes G, Kuang WJ, Goeddel DV, Ferrara N (1989) Vascular endothelial growth factor is a secreted angiogenic mitogen. Science 246:1306-1309. doi:10.1126 /science. 2479986

25. Li H-H, Kedar V, Zhang C, McDonough H, Arya R, Wang D-Z, Patterson C (2004) Atrogin-1/muscle atrophy F-box inhibits calcineurin-dependent cardiac hypertrophy by participating in an SCF ubiquitin ligase complex. J Clin Invest 114:1058-1071. doi:10.1172/JCI22220

26. Mammen PP, Kanatous SB, Yuhanna IS, Shaul PW, Garry MW, Balaban RS, Garry DJ (2003) Hypoxia-induced left ventricular dysfunction in myoglobin-deficient mice. Am J Physiol Heart Circ Physiol 285:2132-2142. doi:10.1152/ajpheart.00147.2003

27. Mavrommatis E, Shioura KM, Los T, Goldspink PH (2013) The Edomain region of mechano-growth factor inhibits cellular apoptosis and preserves cardiac function during myocardial infarction. Mol Cell Biochem 381:69-83. doi:10.1007/s11010-013-1689-4

28. Millward DJ, Garlick PJ, James WP, Nnanyelugo DO, Ryatt JS (1973) Relationship between protein synthesis and RNA content in skeletal muscle. Nature 241:204-205. doi:10.1038/241204a0

29. Molkentin JD, LU JR, Antos CL, Markham B, Richardson JA, Robbins J, Grant SR, Olson EN (1998) A calcineurin-dependent transcriptional pathway for cardiac hypertrophy. Cell 93:215-228. doi:10.1016/S0092-8674(00)81573-1

30. Molojavyi A, Lindecke A, Raupach A, Moellendorf S, Kohrer K, Godecke A (2010) Myoglobin-deficient mice activate a distinct cardiac gene expression program in response to isoproterenol-induced hypertrophy. Physiol Genomics 41: 137-145. doi:10.1152/physiolgenomics.90297.2008

31. Mouchaers KT, Schalij I, Versteilen AM, Hadi AM, van Nieuw Amerongen GP, van Hinsbergh VW, Postmus PE, van der Laarse WJ, Vonk-Noordegraaf A (2009) Endothelin receptor blockade combined with phosphodiesterase- 5 inhibition increases right ventricular mitochondrial capacity in pulmonary arterial hypertension. Am J Physiol Heart Circ Physiol 297: 200-207. doi:10.1152/ajpheart.00893.2008

32. Murray JD (1974) On the role of myoglobin in muscle respiration. J Theor Biol 47:115-126. doi:10.1016/0022-5193(74)90102-7

33. O'Brien PJ, O'Grady M, McCutcheon LJ, Shen H, Nowack L, Horne RD, Mirsalimi SM, Julian RJ, Grima EA, Moe GW, Armstrong PW (1992) Myocardial myoglobin deficiency in various animal models of congestive heart failure. J Mol Cell Cardiol 24: 721-730. doi:10.1016/0022-2828(92)93386-X

34. Pool CW, Scholten G, Diegenbach PC (1979) Quantitative succinate dehydrogenase histochemistry I. A methodological study on mammalian and fish muscle. Histochemistry 64:251-262. doi:10.1007/BF00495025

35. Puigserver $\mathrm{P}, \mathrm{Wu} \mathrm{Z}$, Park CW, Graves R, Wright M, Spiegelman BM (1998) A cold-inducible coactivator of nuclear receptors linked to adaptive thermogenesis. Cell 92:829-839. doi:10.1016/S00928674(00)81410-5

36. Quinsay MN, Thomas RL, Lee Y, Gustafsson AB (2010) Bnip3mediated mitochondrial autophagy is independent of the mitochondrial permeability transition pore. Autophagy 6:855-862. doi:10.4161/auto.6.7.13005

37. Redout EM, Wagner MJ, Zuidwijk MJ, Boer C, Musters RJ, van Hardeveld C, Paulus WJ, Simonides WS (2007) Right-ventricular failure is associated with increased mitochondrial complex II activity and production of reactive oxygen species. Cardiovasc Res 75: 770-781. doi:10.1016/j.cardiores.2007.05.012

38. Regula KM (2002) Inducible expression of BNIP3 provokes mitochondrial defects and hypoxia-mediated cell death of ventricular myocytes. Circ Res 91:226-231. doi:10.1161/01. res.0000029232.42227.16

39. Ruiter G, Manders E, Happé CM, Schalij I, Groepenhoff H, Howard LS, Wilkins MR, Bogaard HJ, Westerhof N, van der 
Laarse WJ, de Man FS, Vonk-Noordegraaf A (2015) Intravenous iron therapy in patients with idiopathic pulmonary arterial hypertension and iron deficiency. Pulm Circ 5:466-472. doi:10.1086 $/ 682217$

40. Ruiter G, Wong YY, de Man FS, Handoko LM, Jaspers RT, Postmus PE, Westerhof N, Niessen HWM, van der Laarse WJ, Vonk-Noordegraaf A (2013) Right ventricular oxygen supply parameters are decreased in human and experimental pulmonary hypertension. J Heart Lung Transplant 32:231-240. doi:10.1016/j.healun.2012.09.025

41. Rumsey WL, Schlosser C, Nuutinen EM, Robiolio M, Wilson DF (1990) Cellular energetics and the oxygen dependence of respiration in cardiac myocytes isolated from adult rat. J Biol Chem 265: 15392-15402

42. Ruwhof C, Van Der Laarse A (2000) Mechanical stress-induced cardiac hypertrophy: mechanisms and signal transduction pathways. Cardiovasc Res 47:23-37. doi:10.1016/S0008-6363(00)00076-6

43. Sacheck JM, Ohtsuka A, McLary SC, Goldberg AL (2004) IGF-I stimulates muscle growth by suppressing protein breakdown and expression of atrophy-related ubiquitin ligases, atrogin-1 and MuRF1. Am J Physiol Endocrinol Metab 287:591-601. doi:10.1152/ajpendo.00073.2004

44. Sano M, Minamino T, Toko H, Miyauchi H, Orimo M, Qin Y, Akazawa H, Tateno K, Kayama Y, Harada M, Shimizu I, Asahara T, Hamada H, Tomita S, Molkentin JD, Zou Y, Komuro I (2007) p53-induced inhibition of Hif-1 causes cardiac dysfunction during pressure overload. Nature 446:444-448. doi:10.1038/nature05602

45. Schenkman KA, Marble DR, Burns DH, Feigl EO (1997) Myoglobin oxygen dissociation by multiwavelength spectroscopy. J Appl Physiol 82:86-92

46. Schlater AE, De Miranda MA, Frye MA, Trumble SJ, Kanatous SB (2014) Changing the paradigm for myoglobin: a novel link between lipids and myoglobin. J Appl Physiol 117:307-315. doi:10.1152/japplphysiol.00973.2013

47. Serneri GG, Modesti PA, Boddi M, Cecioni I, Paniccia R, Coppo M, Galanti G, Simonetti I, Vanni S, Papa L, Bandinelli B, Migliorini A, Modesti A, Maccherini M, Sani G, Toscano M (1999) Cardiac growth factors in human hypertrophy. Relations with myocardial contractility and wall stress. Circ Res 85:57-67. doi:10.1161/01.RES.85.1.57

48. Shoag J, Arany Z (2010) Regulation of hypoxia-inducible genes by PGC-1 alpha. Arterioscler Thromb Vasc Biol 30:662-666. doi:10.1161/ATVBAHA.108.181636

49. Simonides WS, Mulcahey MA, Redout EM, Muller A, Zuidwijk MJ, Visser TJ, Wassen FW, Crescenzi A, da-Silva WS, Harney J, Engel FB, Obregon MJ, Larsen PR, Bianco AC, Huang SA (2008) Hypoxia-inducible factor induces local thyroid hormone inactivation during hypoxic-ischemic disease in rats. J Clin Invest 118:975983. doi:10.1172/JCI32824

50. Sriram R, Kreutzer U, Shih L, Jue T (2008) Interaction of fatty acid with myoglobin. FEBS Lett 582:3643-3649. doi:10.1016/j. febslet.2008.09.047

51. Sutendra G, Dromparis P, Paulin R, Zervopoulos S, Haromy A, Nagendran J, Michelakis ED (2013) A metabolic remodeling in right ventricular hypertrophy is associated with decreased angiogenesis and a transition from a compensated to a decompensated state in pulmonary hypertension. J Mol Med 91:1315-1327. doi:10.1007/s00109-013-1059-4
52. Tang YD, Katz SD (2006) Anemia in chronic heart failure: prevalence, etiology, clinical correlates, and treatment options. Circulation 113:2454-2461. doi:10.1161/circulationaha.105.583666

53. van Beek-Harmsen BJ, Bekedam MA, Feenstra HM, Visser FC, van der Laarse WJ (2004) Determination of myoglobin concentration and oxidative capacity in cryostat sections of human and rat skeletal muscle fibres and rat cardiomyocytes. Histochem Cell Biol 121:335-342. doi:10.1007/s00418-004-0641-9

54. van Beek-Harmsen BJ, Feenstra HM, van der Laarse WJ (2011) Inadequate myocardial oxygen supply/demand in experimental pulmonary hypertension. In: Sulica R, Prestion I (eds) Pulmonary hypertension-from bench research to clinical challenges. InTechEurope, Rijecka, Croatia, pp. 151-166

55. van der Laarse WJ, des Tombe AL, van Beek-Harmsen BJ, Lee-de Groot MBE, Jaspers RT (2005) Krogh's diffusion coefficient for oxygen in isolated Xenopus skeletal muscle fibers and rat myocardial trabeculae at maximum rates of oxygen consumption. J Appl Physiol 99:2173-2180. doi:10.1152/japplphysiol.00470.2005

56. van der Laarse WJ, Diegenbach PC, Elzinga G (1989) Maximum rate of oxygen consumption and quantitative histochemistry of succinate dehydrogenase in single muscle fibres of Xenopus laevis. J Muscle Res Cell Motil 10:221-228

57. van Eif VW, Bogaards SJ, van der Laarse WJ (2014) Intrinsic cardiac adrenergic (ICA) cell density and MAO-A activity in failing rat hearts. J Muscle Res Cell Motil 35:47-53. doi:10.1007/s10974-013-9373-6

58. van Weel V, Deckers MM, Grimbergen JM, van Leuven KJ, Lardenoye JH, Schlingemann RO, van Nieuw Amerongen GP, van Bockel JH, van Hinsbergh VW, Quax PH (2004) Vascular endothelial growth factor overexpression in ischemic skeletal muscle enhances myoglobin expression in vivo. Circ Res 95:58-66. doi:10.1161/01.RES.0000133247.69803.c3

59. van Wessel T, de Haan A, van der Laarse WJ, Jaspers RT (2010) The muscle fiber type-fiber size paradox: hypertrophy or oxidative metabolism? Eur J Appl Physiol 110:665-694. doi:10.1007/s00421-010-1545-0

60. Vonk-Noordegraaf A, Haddad F, Chin KM, Forfia PR, Kawut SM, Lumens J, Naeije R, Newman J, Oudiz RJ, Provencher S, Torbicki A, Voelkel NF, Hassoun PM (2013) Right heart adaptation to pulmonary arterial hypertension. J Am Coll Cardiol 62:22-33. doi:10.1016/j.jacc.2013.10.027

61. Weeks KL, McMullen JR (2011) The Athlete's heart vs. the failing heart: can signaling explain the two distinct outcomes? Physiology 26:97-105. doi:10.1152/physiol.00043.2010

62. Witt CC, Witt SH, Lerche S, Labeit D, Back W, Labeit S (2008) Cooperative control of striated muscle mass and metabolism by MuRF1 and MuRF2. EMBO J 27:350-360. doi:10.1038/sj.emboj.7601952

63. Wittenberg BA, Wittenberg JB, Caldwell PR (1975) Role of myoglobin in the oxygen supply to red skeletal muscle. J Biol Chem 250:9038-9043

64. Wittenberg JB (2003) Myoglobin function reassessed. J Exp Biol 206:2011-2020. doi:10.1242/jeb.00243

65. Wong YY, Handoko ML, Mouchaers KT, de Man FS, VonkNoordegraaf A, van der Laarse WJ (2010) Reduced mechanical efficiency of rat papillary muscle related to degree of hypertrophy of cardiomyocytes. Am J Physiol Heart Circ Physiol 298:H1190 H1197. doi:10.1152/ajpheart.00773.2009 